\title{
PERBEDAAN LATIHAN INTERVAL, SIRKUIT TRAINING, DAN LARI JARAK JAUH TERHADAP PENINGKATAN KEBUGARAN AEROBIK PADA ATLET BOLA BASKET DI MAN 2 SEMARANG
}

\author{
Muhammad Dwi Kurniawan ${ }^{1}$, Maskun Pudjianto ${ }^{2}$ \\ ${ }^{1,2}$ Program Studi Fisioterapi Fakultas Ilmu Kesehatan Universitas Muhammadiyah \\ Surakarta. Jl. A. Yani Tromol Pos I Pabelan Surakarta. \\ Email:1auwalistiz.08@gmail.com, ${ }^{2}$ pudjiantomaskun@gmail.com
}

\begin{abstract}
ABSTRAK
Pentingnya latihan aerobik pada atlet adalah untuk meningkatkan stamina atlet, sehingga pada saat pertandingan atlet tidak mudah merasa lelah. Tujuan dari penelitian ini adalah untuk mengetahui perbedaan latihan interval, sirkuit training, dan lari jarak jauh terhadap peningkatan kebugaran aerobik. Tujuan penelitian adalah untuk mengetahui perbedaan latihan interval, sirkuit training, dan lari jarak jauh terhadap peningkatan kebugaran aerobik. Penelitian ini menggunakan metode eksperimental semu atau Quasi experiment. Penelitian menggunakan three group pre-test and post-testdesign untuk mengetahui manfaat program latihan aerobik yang terencana selama 4 minggu. Teknik pengambilan sampel menggunakan nonprobability sampling dengan teknik purposive sampling yang dipilih dari populasi serta memenuhi kriteria inklusi dan eksklusi. Uji normalitas data dilakukan dengan uji Sapiro-Wilk. Selanjutnya data diuji menggunakan Paired Simple T Test dan Mean Deference. Hasil penelitian ini adalah nilai $t$ hitung dari latihan interval $=-4.341$ dengan sig. 0.007, sirkuit training $=-2.907$ dengan sig. 0.034 dan lari jarak jauh $=-7.225$ dengan sig.0.001. Ketiga jenis program latihan yang diberikan memiliki nilai sig. $<0.05$, artinya bahwa latihan interval, sirkuit training, dan lari jarak jauh dapat mempengaruhi kebugaran aerobik. Secara statistik, ada perbedaan latihan interval, sirkuit training, dan lari jarak jauh terhadap peningkatan kebugaran aerobik.
\end{abstract}

Kata kunci : Kebugaran aerobik, lari jarak jauh, latihan interval, sirkuit traning,

\begin{abstract}
The importance of aerobic exercise in athletes is to increase the athlete's stamina so that during the game, athletes do not feel tired. The objective of the study was to determine the difference between interval training, training circuits, and long-distance runs to increase aerobic fitness. The study used three groups of pre-test and post-test design to determine the benefits of a planned 4-week aerobic exercise program. The sampling used was Nonprobability with purposive sampling technique, selected from the population and adjusted the criteria of inclusion and exclusion. The data normality test used was
\end{abstract}


the Sapiro-Wilk test. Further data were analyzed using Paired Simple T-Test and Mean Deference. The result displayed that the t-value of interval training was -4.341 with the sig. 0.007 . The training circuit was -2.907 with the sig. 0.034 . The long-distance run $=-7.225$ with the sig. 0.001 . The three types of training programs provided have a sig. value $<0.05$, meaning that interval training, training circuits, and long-distance running can affect aerobic fitness. Statistically, there were differences in interval training, training circuits, and longdistance runs for aerobic fitness improvement.

Keywords: Aerobics fitness, long-distance run, interval training, training circuit

\section{PENDAHULUAN}

Proses menjadi kuat dalam sudut pandang kesehatan dapat dilihat melalui tingkat kebugaran yang dimiliki seseorang. Salah satu cara untuk meningkatkan kebugaran adalah dengan cara berolahraga secara teratur. Ada banyak cabang olahraga yang dapat meningkatkan kebugaran pada manusia, misalnya sepak bola, volley ball, bulu tangkis dan bola basket.

Menurut peraturan resmi bola basket yang diambil dari PERBASI (2012), pertandingan bola basket merupakan permainan yang dimainkan oleh dua tim yang masing-masing terdiri dari lima pemain. Tujuan dari masing-masing tim adalah untuk mencetak angka ke ranjang lawan dan berusaha mencegah tim lawan mencetak angka. Dalam pertandingan, permainan dipimpin oleh wasit dan tim dinyatakan menjadi pemenang apabila mampu mencetak angka lebih banyak dari tim lawan pada akhir waktu permainan.

Berkaitan dengan kebugaran, olahraga merupakan cara terbaik untuk memelihara, menjaga, dan meningkatkan kondisi fisik secara maksimal. Latihan fisik yang dilakukan secara berulang dan teratur akan memberikan hasil berupa tubuh yang sehat, yang ditandai dengan ketahanan otot yang kuat, sistem kardiorespirasi yang optimal, dan berat badan yang seimbang. Proses peningkatan sistem kardio-respirasi dapat menggunakan program berupa latihan aerobik, karena dengan latihan ini seseorang mampu mengoptimalkan fungsi jantung dan paruparunya.

Tes kebugaran jasmani penting dilakukan agar diketahui seberapa besar kebugaran jasmani yang dimiliki pada setiap latihan aerobik. Hasil dari tes kebugaran jasmani dapat dijadikan sebagai acuan dalam mengevaluasi kekuatan dan kelemahan yang dimiliki oleh atlet. Dalam pemeriksaan kebugaran aerobik yang difungsikan untuk mengetahui cara mengukur kapasitas maksimal tubuh (VO2max), terdapat beberapa alat ukur, dan pada penelitian ini penelitian menggunakan alat ukur Multistage Fitness Test (MFT).

Pada aplikasinya latihan kebugaran aerobik mempunyai banyak variasi dengan tetap berpegang pada prinsip dasar kebugaran aerobik seperti kontrol respirasi, kerja jantung maksimal, dan kesesuaian sistem aerobik dan anaerobik (Ashadi, 2014). Prinsip dasar tersebut dapat dijadikan sebagai patokan untuk membuat berbagai variasi program latihan khususnya latihan aerobik seperti misalnya latihan interval, sirkuit training, dan lari jarak jauh. Latihan interval merupakan latihan dengan memanfaatkan kontrol pernafasan dominan yang 
menggunakan fase istirahat saat latihan. Sirkuit training adalah program latihan yang menggunakan prinsip kombinasi antara sistem aerobik dan anaerobik dengan memodifikasi latihan dan pembebanan. Dan lari jarak jauh adalah termasuk jenis latihan yang dimanfaatkan untuk memaksimalkan kerja jantung agar volume oksigen yang masuk kedalam tubuh lebih besar.

Dari uraian diatas untuk melihat efektifitas dan ketepatan dalam pemberian program latihan yang baik maka peneliti tertarik untuk melakukan penelitian tentang perbedaan latihan interval, sirkuit training, dan lari jarak jauh terhadap peningkatan kebugaran aerobik pada atlet bola basket di MAN 2 Semarang.

\section{METODE PENELITIAN}

Penelitian ini menggunakan metode eksperimental semu atau Quasi experiment yang bertujuan untuk mengetahui pengaruh yang timbul akibat dari adanya perlakuan yang diberikan dengan frekuensi dan intensitas yang berbeda. Dengan menggunakan desain three group pre-test and post-test with group design yaitu untuk mengetahui manfaat program latihan aerobik yang terencana selama 4 minggu terhadap kebugaran kardio-respirasi pada atlet bola basket MAN 2 Semarang.

Penelitian ini dilaksanakan di Lapangan Basket MAN 2 Semarang, selama 4 minggu dari tanggal 5-31 Desember 2016 dengan durasi 3 kali perminggu setiap hari selasa, kamis, dan sabtu. Penelitian dimulai pukul 15.30 WIB selama 30 menit $(10$ menit pemanasan dan 20 menit pelaksanaan program latihan). Populasi adalah keseluruhan suatu variabel menyangkut masalah yang diteliti, variabel tersebut bisa berupa orang, kejadian, perilaku, atau sesuatu yang akan dilakukan penelitian
(Notoatmodjo, 2012). Populasi dalam penelitian ini adalah seluruh siswa pria yang mengikuti ekstra kulikuler Basket di MAN 2 Semarang yang berjumlah 18 orang.

Teknik pengambilan sampel menggunakan nonprobability sampling dengan teknik purposive sampling yang dipilih dari populasi serta memenuhi kriteria inklusi dan eksklusi (Notoatmodjo, 2012). Subyek yang telah memenuhi kriteria inklusi akan di kelompokan menjadi 3 kelompok perlakuan tanpa kelompok kontrol. Pengelompokan di awali dengan melakukan pretest untuk mengetahui nilai VO2max masing-masing responden dengan menggunakan MFT atau bleep test. Setelah dilakukan pretest pada seluruh responden, maka dilanjutkan pada tahap pembagian kelompok. Pembagian kelompok diperoleh dari matching nilai bleep test awal yang dirancang sedemikian rupa sehingga masing-masing kelompok itu berangkat dari titik tolak yang sama.

Enam responden yang memiliki nilai bleep test terbaik kedua masuk dalam kelompok I dengan pemberian latihan interval, enam responden yang memiliki nilai bleep test tertinggi masuk dalam kelompok II dengan diberikan sirkuit training, dan enam kelompok yang memiliki nilai bleep test terendah akan dimasukan kedalam kelompok III dengan program latihan lari jarak jauh. Selanjutnya adalah pelaksanaan program latihan seminggu 3 kali selama 4 minggu kemudian dilakukan tahap akhir berupa posttest. Pengukuran dilakukan untuk mengetahui peningkatan kebugaran aerobik. Hasil posttest yang didapat digunakan untuk membandingkan ketiga kelompok perlakuan untuk menentukan efektifitas latihan aerobik yang lebih baik.

Setelah data terkumpul, dilakukan pengolahan data menggunakan komputer 
dengan program SPSS 16.0, kemudian dilakukan uji normalitas data dengan uji Shapiro Wilk. Kemudian data yang terdistribusi normal dilanjutkan dengan uji hipotesis berupa paired Simple T test untuk mengatahui ada tidaknya pengaruh pre dan posttest. Apabila program latihan yang diberikan memiliki nilai sig $<0.05$ maka dapat disimpulkan bahwa Ho ditolak, artinya rata-rata hasil level MFT sebelum dan sesudah perlakuan adalah berbeda. Dengan demikian dapat dinyatakan bahwa latihan interval, sirkuit training, dan lari jarak jauh dapat mempengaruhi kebugaran aerobik.

\section{HASIL DAN PEMBAHASAN}

\section{Uji Normalitas (Shapiro Wilk)}

Perhitungan uji normalitas data menggunakan sistem perhitungan dengan bantuan software SPSS 16.0 pada penelitian ini jumlah sampel kurang dari 50, maka digunakan uji Shapiro-Wilk Test, data dikatakan normal bila (p) > 0,05 . Berdasarkan output test of normality, diperoleh nilai probabilitas sig. untuk pre test sebesar 0,101 untuk latihan interval, sirkuit training memperoleh nilai 0,679 , dan nilai probabilias sig. dari lari jarak jauh adalah sebenyak 0,128 . Sedangkan nilai probabilitas sig. Untuk posttest menghasilkan nilai sebanyak 0,773 untuk latihan interval, 0,672 untuk sirkuit training, dan lari jarak jauh bernilai 0,384. Karena ketiga program latihan memiliki nilai probabilitas sig. pada pre dan posttest lebih besar (>) 0,05 maka dapat disimpulkan bahwa ketiga data berdistribusi normal (Dahlan, 2009).

Setelah hasil pengujian normalitas data membuktikan bahwa variabel sebelum dan sesudah perlakuan pada kelompok eksperimen I, II, dan III diperoleh nilai probabilitas $(\mathrm{p})>0,05$ yang artinya semua data berdistribusi normal, maka data akan dilanjutkan pada uji Hipotesis dengan uji Paired Simple T Test.

\section{Uji Hipotesis (Paired Simple T Test)}

Setelah dilakukan uji statistik hipotesis non parametrik dengan Paired Simple T Test pada ketiga perlakuan di atas, maka untuk menunjukan ada atau tidaknya korelasi nilai statistik dari sebelum dan sesudah perlakuan dilakukan perbandingan antara sig. atau nilai probabilitas masing-masing latihan dengan level of significant 0,05 . Pada uji hipotesis menunjukan bahwa nilai t hitung dari latihan interval $=-4.341$ dengan sig. 0.007 , sirkuit training $=-2.907$ dengan sig. 0.034. dan lari jarak jauh $=-7.225$ dengan sig. 0.001. Karena ketiga jenis program latihan yang diberikan memiliki nilai sig < 0.05 maka dapat disimpulkan bahwa Ho ditolak, artinya rata-rata hasil level MFT sebelum dan sesudah perlakuan adalah berbeda. Dengan demikian dapat dinyatakan bahwa latihan interval, sirkuit training, dan lari jarak jauh dapat mempengaruhi kebugaran aerobik.

\section{Mean Of Deference}

Mean Of Deference dilakukan untuk membuktikan adanya beda rata-rata setiap program latihan untuk pre dan posttest. Latihan interval memiliki rata- rata pre test sebesar 5.550 dan posttest sebesar 5.900, selanjutnya sirkuit training memiliki rata- rata pretest sebesar 7.110 dan posttest sebesar 7.230, dan terakhir lari jarak jauh yang memiliki rata- rata pretest sebesar 4.460 dan posttest sebesar 5.150. Hasil dari Mean Of Deference juga menunjukan bahwa nilai perbedaan ratarata kelompok eksperimen latihan interval adalah sebesar 0.35, kelompok eksperimen sirkuit training sebesar 0.12 , dan kelompok lari jarak jauh sebesar 0.68. Hal ini berarti bahwa kelompok eksperimen lari jarak jauh mampu meningkatkan kebugaran aerobik lebih 
baik dari pada kelompok eksperimen latihan interval dan sirkuit training dengan alat ukur yang digunakan adalah MFT.

Pada latihan interval yang memanfaatkan fase istirahat selama 2 menit memberikan hasil peningkatan dengan selisih rata-rata sebanyak 0,35 . Waktu istirahat difungsikan untuk mengontrol pernapasan saat latihan. Latihan ini akan menimbulkan peningkatan pada permiabilitas hidung sehingga terjadi perubahan vaskuler pada dinding lateral hidung yang di akhiri dengan peningkatan volume udara yang masuk di dalam hidung (Marconi dkk., 2006). Dalam penelitian sejenis yang pernah dilakukan oleh Widodo (2010), juga membuktikan bahwa latihan interval mampu meningkatkan kebugaran aerobik. Dalam penelitiannya yang membandingkan efektifitas work interval dan rest interval (latihan interval tanpa fase istirahat dan penggunaan fase istirahat) disimpulkan bahwa rest interval lebih baik daripada work interval dengan peningkatan sebesar 7,084 \% .

Hasil peningkatan selisih rata- rata yang diperoleh dari sirkuit training adalah sebanyak 0,12. Peneliti memanfaatkan bola sebagai media atau pembebanan dalam latihan dan mengkombinasikannya dengan beberapa teknik dalam keterampilan basket. Dengan adanya pembebanan dan kombinasi tersebut latihan sirkuit training dimaksudkan untuk mengkorelasikan latihan aerobik dan anaerobik dalam proses peningkatan VO2max atlet. Karena pada prinsipnya pemakaian oksigen tidak dapat meningkat lebih cepat dari volume pemberian oksigen pada atlet saat bertanding maka kerja tubuh membutuhkan bantuan sistem anaerobik saat bertanding basket atau beraktifitas (Sukmaningtyas dkk., 2004). Manfaat dari sirkuit training adalah untuk meningkatkan ambang rangsang anaerobik untuk meningkatkan kualitas kerja sistem aerobik (Giriwijoyo dan Sidik, 2012). Kombinasi program latihan juga pernah dilakukan pada penelitian sebelumnya oleh Becker dan Will (2015). Pada penelitian tersebut peneliti mengintegrasikan prinsip biomekanik dan motor kontrol terhadap peningkatan jumper tinggi elit. Tujuan dari penelitian ini adalah untuk mengetahui efektifitas dari penggunaan prinsip biomekanik dan motor kontrol untuk meningkatkan kinerja atlet dalam lompat tinggi. Pada penelitian tersebut responden yang diambil sebanyak empat orang jumper. Pelaksanaan dibagi dalam dua kali lompatan, yang pertama jumper melompat secara normal dan yang kedua jumper diberikan pemahaman tentang prinsip biomekanik dan motor kontrol sebelum melakukan lompatan. Dari keempat orang jumper yang melakukan lompatan membuktikan bahwa hasil yang diperoleh adalah terdapat penurunan efek latihan pada waktu dan titik akhir lompatan sebanyak 1,32 dan mengalami peningkatan pada kecepatan lompatan sebanyak 1,53.

Pada latihan lari jarak jauh yang dilakukan menghasilkan selisih rata-rata sebanyak 0,68. Fokus utama program latihan ini adalah lebih pada peningkatan efektifitas kerja kardiorespirasi yang terjadi karena kapasitas difusi pada latihan ini lebih baik. Semakin meningkatnya kapasitas difusi paru maka volume gas yang berdifusi juga meningkat sehingga kemampuan kardiorespirasi menjadi semakin baik (Muchamad, Maqsalmina dan Pudjonarko, 2005). Dengan kemampuan kardiorespirasi tersebut, seseorang akan bernapas lebih lambat dan lebih dalam sehingga kerja jantung lebih ringan karena jumlah oksigen yang masuk lebih banyak dalam sekali denyutan jantung. Penelitian ini terlihat relevan, jika dibandingkan dengan penelitian yang dilakukan oleh Dixon dkk. (2014). Dalam penelitian tersebut peneliti mencoba 
membandingkan pengaruh lari aerobik 400 dengan repetisi dan set yang berbeda terhadap peningkatan kemampuan fisik siswa SMPN Denpasar kelas VII yang mengikuti perlombaan jalan cepat 3000 meter. Pada kelompok I peneliti memberikan pelatihan lari aerobik 400 meter dengan 3 repetisi dan 2 set, sedang pada kelompok II peneliti memberikannya dengan 2 repetisi dan 3 set. Penelitian tersebut memiliki efek yang hampir sama dengan peningkatkan kebugaran yang relatif tinggi. Pada penelitian didapat hasil bahwa kedua kelompok mengalami peningkatan yang dibuktikan dengan alat ukur Stopwatch. Pada kelompok I dalam hitungan diperoleh hasil peningkatan kecepatan antara pre dan posttest dengan stopwatch. Hasil uji kecepatan jalan cepat 3000 meter dengan uji $t$ paired test pada kelompok I menghasilkan rata- rata kecepatan pretest sebanyak 24,8875 menit dan rata- rata posttest sebanyak 22,7400 menit. Sedangkan uji $t$ paired test pada kelompok II menghasilkan nilai rata- rata kecepatan pretest sebanyak 24,8756 menit dan memiliki rata-rata sebanyak 23,5794 menit. Hal tersebut membuktikan bahwa 3 repetisi dan 2 set mempunyai peningkatan lebih baik dengan beda rata-rata sebesar 2,14 menit daripada 2 repetisi 3 set yang hanya memiliki beda rata-rata sebesar 1,3 menit.

Dari hasil yang diperoleh di atas, perbedaan efektifitas pada ketiga program pada dasarnya tidaklah signifikan. Latihan interval, sirkuit training, dan lari jarak jauh memberikan hasil yang baik terhadap peningkatan VO2max yang dibuktikan dengan adanya peningkatan nilai rata-rata masing-masing latihan dengan efektifitas terbaik terjadi pada latihan lari jarak jauh. Dengan mencoba memaksimalkan kapasitas kerja jantung saat berlari, latihan lari jarak jauh mampu menghasilkan beda rata- rata level MFT sebanyak 0.68. Peningkatan aktifitas kerja jantung secara maksimal pada lari jarak jauh akan mengaktifasi kerja otot- otot besar melalui latihan berintensitas tinggi sehingga frekuensi denyut jantung akan meningkat (Suharjana, 2012).

\section{Keterbatasan Penelitian}

Dalam pelaksanaan penelitian tentang perbedaan pengaruh latihan interval, sirkuit training, dan lari jarak jauh terhadap peningkatan kebugaran aerobik pada alet bola basket di MAN 2 Semarang memiliki keterbatasan, antara lain kondisi atlet dan jumlah sampel yang minimal. Selain itu, faktor lain yang menghambat adalah penelitian yang dibuat merupakan eksperimen semu yang hanya menitikberatkan pada pengaruh latihan interval, sirkuit training, dan lari jarak jauh terhadap peningkatan VO2max sehingga kurangnya kontrol terhadap kegiatan lain yang dapat mempengaruhi peningkatan VO2max seperti kondisi responden, kegiatan di luar/aktivitas sehari-hari, asupan nutrisi, dan lain sebagainya.

\section{KESIMPULAN}

a) Adanya pengaruh ketiga program latihan terhadap peningkatan kebugaran aerobik. Latihan interval memiliki rata-rata level MFT pre dan post test sebesar 0.35 , peningkatan rata-rata level MFT pre dan posttest pada Sirkuit training sebesar 0.12, dan lari jarak jauh mengalami peningkatan rata-rata level bleep test/ MFT pre dan posttest sebesar 0.68 .

b) Melalui data yang diperoleh dari selisih rata-rata diatas membuktikan bahwa lari jarak jauh mempunyai efektifitas atau pengaruh yang paling tinggi daripada sirkuit training dan lari interval dengan nilai selisih rata-rata 0.68, dilanjutkan dengan latihan interval yang bernilai 0.35 , dan yang 
terakhir adalah sirkuit training dengan jumlah 0.12. Konsep dasar yang di bangun pada lari jarak jauh adalah dengan meningkatkan aktifitas kerja jantung melalui aktifasi kerja otot- otot besar yang menggunakan latihan berintensitas tinggi agar frekuensi denyut jantung dapat meningkat.

\section{DAFTAR PUSTAKA}

Ashadi, Kunjung., 2014, Implementasi Fisiologi Olahraga Prestasi, Pertemuan Ilmiah Ilmu Keolahragaan Nasional 2014, Surabaya.

Becker, J dan Will, F.W. Wu., 2015, Integrating biomechanical and motor control principles in elite high jumpers: A transdisciplinary approach to enhancing sport performance. Department of Kinesiology, California State University, California.

Dahlan, M.S., 2009, Statistik untuk Kedokteran dan Kesehatan, Edisi 4 (Deskriptif, Bivariat dan Multivariat, dilengkapi Aplikasi dengan Menggunakan SPSS), Salemba Medika, Jakarta.

Dixon E. M. Taek Bete, I Ketut Tirtayasa, dan I Made Jawi., 2014, Pelatihan Aerobik 400 Meter Tiga Repetisi Dua Set Dan Dua Repetisi Tiga Set Selama 6 Minggu Sama-Sama Meningkatkan Kecepatan Jalan Cepat 3000 Meter Siswa Kelas VII SMP N 11 Denpasar, Sport and Fitness Journal, vol.02 no.2 halaman: 39-52.

Giriwijoyo, S. dan Sidik, D. Z., 2012, Ilmu Faal Olahraga (Fisiologi Olahraga). PT Remaja Rosdakarya, Bandung.

Marconi, Teixeira Fonseca., Juliana, Altavilla van Petten Machado., Soraya, Alves Pereira., Kelerson, Moura Pinto., Richard Louis Voegels., 2006, Effects of Physical Exercise in Nasal Volume. Sao Paulo : Brazilian Journal of Otorhinolaryngology, University Of Sao Paulo (Fmusp), Brazil.

Muchamad, Masalmina dan Pujonarko, D. 2005. Influence Of Programmed Aerobic Exercise To VO2max Change of 12 to 14 Years Old Football School Student. Diponegoro Univercity, Semarang.

Notoatmodjo., 2012, Metodologi Penelitian Kesehatan, PT. Rineka Cipta, Jakarta.

PB. PERBASI., 2012, Buku Peraturan Resmi Bola Basket 2012, PB. Perbasi 2012, Jakarta.

Suharjana., 2012, Pentingnya Kebugaran Aerobik Bagi Setiap Atlet Yang Bertanding Pada Kejuaraan Multi Event, Yogyakarta: Medikora, vol. 09 no. 01. 
Sukmaningtyas, H., Pudjonarko, D., dan Basjar, E., 2004, Pengaruh Latihan Aerobik dan Anaerobik terhadap Sistem Kardiovaskuler dan Kecepatan Reaksi, Medika Media Indonesia, hal 39: 74-9.

Widodo, Slamet., 2010, Pengaruh Perbedaan Rasio Work Interval Dan Rest Interval Terhadap Kecepatan Lari, Universitas Sebelas Maret (UNS), Surakarta. 